\title{
TINGKAT PENGETAHUAN PASIEN TERHADAP DAGUSIBU OBAT DITENGAH PANDEMI COVID-19 DI KLINIK RITA MEDIKA CISIRUNG PERIODE APRIL-MEI 2021 \\ Dyah Pramesti dan Meiti Rosmiati
}

Politeknik Piksi Ganesha Bandung, Indonesia

E-mail: dyahpramesti48@gmail.com dan maytearose@gmail.com

Diterima:

18 Oktober 2021

Direvisi:

05 November

2021

Disetujui:

15 November

2021

\section{Abstrak}

Dagusibu merupakan program dari Ikatan Apoteker Indonesia dalam menggarakan masyarakat dalam pemakaian obat dengan baik agar saat swamedikasi masyarakat telah paham bagaimana cara mendapatkan, menggunakan, menyimpan dan membuang obat dengan benar, Kasus resistensi antibiotik di kalangan masyarakat dan kesalahan dalam penyimpanan obat menjadi latar belakang permasalahan pada laporan ini maka tujuan penelitian ini adalah untuk mengetahui tingkat pengetahuan masyarakat tentang Dagusibu obat berdasarkan umur, dan tingkat pendidikan. Penelitian ini termasuk dalam penelitian deskriptif dengan pendekatan kuantitatif, dan skala yang digunakan adalah skala Guttman dan skala Likert. Untuk mengukur hasil dari pengetahuan terhadap obat menggunakan skoring modek skala Guttman yaitu Ya, Tidak, dan Tidak tahu. Dimana responden yang menjawab pertanyaan kuesioner dengan benar akan mendapat nilai 1, salah akan mendapat nilai 0 , dan tidak tahu dianggap 0. Penelitian menggunakan skala Guttman dikarenakan ingin mendapat jawaban yang tegas dari responden tentang pertanyaan-pertanyaan yang ada pada kuesioner penelitian. Hasil dari penelitian yang diperoleh menunjukan bahwa tingkat pengetahuan pasien berdasarkan umur, berpengetahuan kurang sebesar $27,5 \%$. Sedangkan pada tingkat pengetahuan berdasarkan pendidikan persentase berpengatahuan kurang sebesar 32,5\%. TTK yang bertugas dalam pemberian obat kepada pasien selalu memberikan edukasi kepada pasien sehingga tingkat pengetahuan pasien terhadap Dagusibu obat dan swamedikasi tidak terlalu rendah.

Kata kunci: Dagusibu, Swamedikasi, Edukasi

Abstract
Dagusibu is a program of the Ikatan Apoteker Indonesia in which
he defined society in good use of medicine so that in self
medication people would understand how to get, use, store
medicine, and dispose of the medicine properly. The purpose of
this study is to find out the level of public knowledge about
dagusibu drugs based on age, and the level of education. In this
study the scale used is the Guttman scale and the Likert scale. To
measure the results of knowledge of drugs using guttman scale
modek score that is Yes, No, and Do not know. Where respondents
who answered the questionnaire question correctly will get a
score of 1, wrong will get a score of 0, and do not know it is
considered 0. The study used the Guttman scale because it wanted




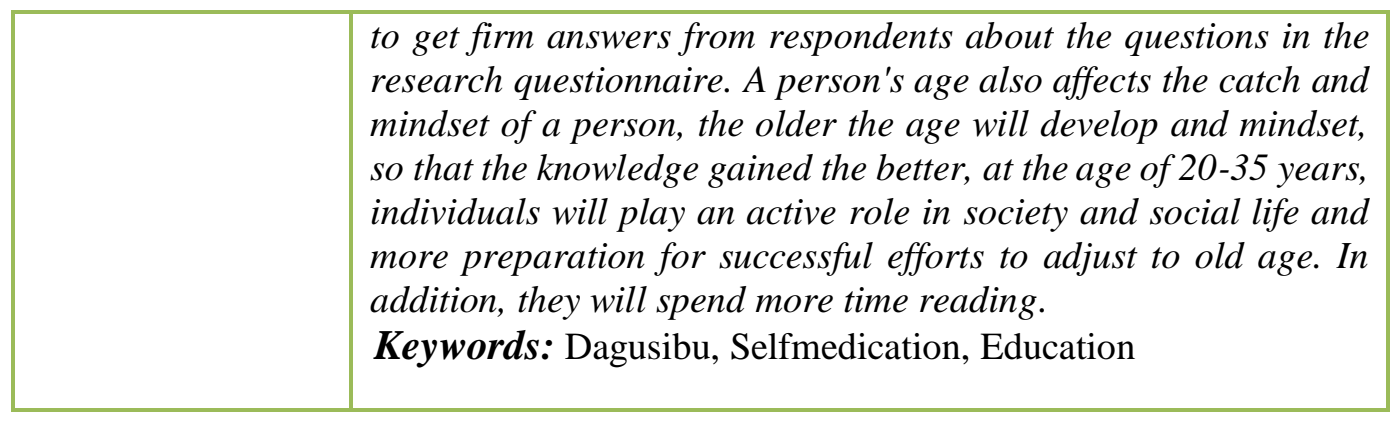

\section{Pendahuluan}

Swamedikasi adalah penggunaan obat-obatan seseorang untuk mengobati segala keluhan ringan pada diri sendiri atas inisiatif sendiri atau tanpa konsultasi medis yang berkaitan dengan indikasi, dosis, dan lama penggunaan (Asnasari, 2017). Di Indonesia, pengobatan dapat dilakukan secara mandiri menggunakan obat tradisional dan obat konvensional baik dari golongan obat bebas maupun obat bebas terbatas. Keuntungan dari swamedikasi salah satunya yaitu mengurangi beban pelayanan medis dan obat untuk mengatasi keluhan-keluhan ringan, sering kali sudah tersedia dirumah. Disisi lain, terdapat risiko dari swamedikasi yaitu gejala tersamarkan dan tidak dikenali yang sebenarnnya merupakan penyakit serius serta risiko efek samping dari pemakaian obat yang kurang tepat (Dewi, Agustina, \& Husna, 2020).

Di Indonesia sendiri perilaku pengobatan sendiri sudah memiliki nilai yang cukup besar. Salah satunya ciri adanya swamedikasi adalah dengan perilaku Rumah Tangga yang menyimpan obat untuk pengobatan diri sendiri (Diantami, 2018). Dimana data menunjukan sebesar 35,2\% rumah tangga telah menyimpan obat untuk swamedikasi. Prakteknya terdapat obat keras, obat bebas, antibiotik, obat tradisional dan obat-obat yang tidak teridentifikasi. Dengan adanya obat keras dan antibiotik untuk swamedikasi menunjukan adanya penggunaan obat yang tidak rasional (Khairiyati, 2015). Penggunaan pengobatan sendiri ini harus mengikuti prinsip penggunaan obat secara umum yaitu penggunaan obat aman dan rasional. Sebagai seorang professional kesehatan dalam bidang kefarmasian, apoteker mempunyai peran yang sangat penting dalam memberikan bantuan, nasehat dan petunjuk kepada masyarakat yang ingin melakuakan swamedikasi agar pasien dapat melakukan secara bertanggung jawab (Khuluq, 2020).

Obat merupakan semua bahan tunggal atau campuran yang digunakan oleh semua makhluk untuk bagian dalam maupun luar, guna mencegah, meringankan, maupun menyembuhkan penyakit (Shelawati, 2019). Meskipun obat dapat menyembuhkan tapi banyak kejadian yang mengakibatkan seseorang menderita akibat keracunan obat. Obat akan bersifat sebagai obat apabila tepat digunakan dalam pengobatan suatu penyakit dengan dosis dan waktu yang tepat (Utami, 2012). Agar obat mencapai tempat aksinya, sifat obat dan cara pemakaian obat harus diketahui agar tepat dan aman dalam menggunakannya (Majid, 2020). Ketidak patuhan pasien dalam mengonsumsi obat dikarenakan kurangnya pemahaman pasien terhadap terapi yang sedang dijalaninya (Bachrun, 2017). Kurangnya informasi tentang pengobatan dan informasi tentang obat yang dikonsumsi menjadi penyebab ketidakpatuhan pasien tersebut terjadi (Puspaningrum, 2020). Informasi obat yang tepat dan terkini merupakan pelayanan yang diperlukan dalam upaya penggunaan obat yang rasional oleh pasien (Tumiwa, 2014). 
Hasil penelitian kesehatan dasar tahun 2013 menunjukan bahwa 35,2\% masyarakat Indonesia menyimpan obat untuk pengobatan sendiri di rumah tangga, baik di peroleh dari resep dokter maupun membeli secara bebas, diantaranya sebesar $27,8 \%$ adalah antibiotik dan $35,7 \%$ obat keras, hal ini nantinya perlu adanya edukasi untuk masyarakat seperti dilakukan sosialisasi tentang Dagusibu obat dan sebagai usulan untuk dinas-dinas yang terkait (Soleha et al., 2018). Karena jika penggunaanya salah, tidak tepat dan tidak sesuai dengan takaran dan indikasi maka obat dapat membahayakan kesehatan. Perbedaan penelitian kali ini diambil pada saat masa pandemi dimana banyak masyarakat sekitar melakukan swamedikasi. Tujuan penelitian ini adalah mengetahui tingkat pengetahuan masyarakat tentang Dagusibu obat berdasarkan umur, dan tingkat pendidikan. Manfaat penelitian ini yaitu menambah edukasi kepada masyarakat mengenai cara mendapatkan, menggunakan, menyimpan, dan membuang obat dengan benar.

\section{Metode Penelitian}

Pada penelitian ini menggunakan metode penelitian deskriptif, dengan teknik pengumpulan data menggunakkan kuesioner, skala yang digunakan adalah skala Guttman dan skala Likert. Untuk mengukur hasil dari pengetahuan terhadap obat menggunakan skoring modek skala Guttman yaitu Ya, Tidak, dan Tidak tahu. Dimana responden yang menjawab pertanyaan kuesioner dengan benar akan mendapat nilai 1, salah akan mendapat nilai 0, dan tidak tahu dianggap 0. Penelitian menggunakan skala Guttman dikarenakan ingin mendapat jawaban yang tegas dari responden tentang pertanyaan-pertanyaan yang ada pada kuesioner penelitian.

\section{Hasil dan Pembahasan}

Penelitian dilakukan di Klinik Rita Medika Desa Cangkuang Wetan, Kecamatan Dayeuhkolot, Kabupaten Bandung bertujuan untuk mengetahui sejauh mana pengetahuan pasien tentang Dagusibu, dan memberikan sedikit edukasi agar tidak adanya lagi kesalahan dalam swamedikasi.

Tabel 1. Karakteristik Responden Berdasarkan Jenis Kelamin.

\begin{tabular}{llll}
\hline No. & Jenis Kelamin & Jumlah & Persentase (\%) \\
\hline 1. & Perempuan & 25 & 62,5 \\
2. & Laki-laki & 15 & 37,5 \\
\hline & Total & 40 & 100
\end{tabular}

Sumber: Data primer penelitian 2021
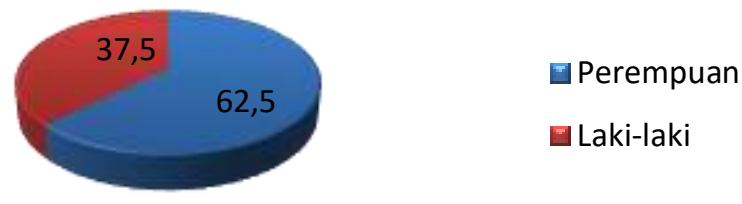

Gambar 1. Persentase Jumlah Responden berdasarkan Jenis kelamin.

Berdasarkan hasil tabel 1 menunjukan bahwa jumlah responden perempuan lebih banyak, dengan persentase 62,5\% dan laki-laki 37,5\%. Menurut WHO (dikutip dalam Hurlock, 2009) umur seseorang dapat diklasifikasi sebagai berikut, dewasa awal 18-40 tahun, dewasa akhir 41-65 tahun, lansia >65 tahun. 
Tabel 2. Karakteristik Responden Berdasarkan Umur

\begin{tabular}{cccc}
\hline No. & Umur & Jumlah & Persentase $(\%)$ \\
\hline 1. & $(18-40$ tahun $)$ & 26 & 65 \\
2. & $(41-65$ tahun $)$ & 14 & 35 \\
\hline & Total & 40 & 100
\end{tabular}

Sumber: Data primer penelitian 2021

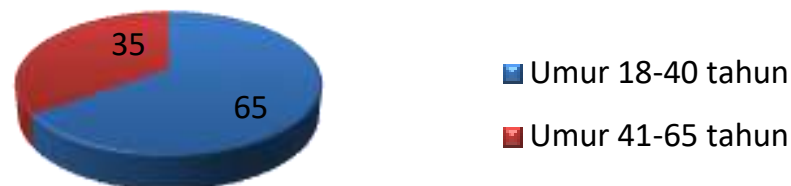

Gambar 2. Persentase jumlah responden berdasarkan umur.

Berdasarkan tabel 2 menunjukan bahwa responden terbanyak ada pada rentang usia dewasa (18-40 tahun) sebedar 65\% dan kategori umur terkecil ada pada rentang umur tua (41-65 tahun) sebesar 35\%. Tingkat pendidikan menurut Undang-Undang No.20 Tahun 2003 :

a. Pendidikan dasar atau rendah (SD-SMP/MTs)

b. Pendidikan menengah (SMA/SMK)

c. Pendidikan tinggi (D3/S1)

Dalam penelitian ini, peneliti menggunakan kategori tingkat pendidikan rendah, menengah dan tingkat pendidikan tinggi.

Tabel 3. Karakteristik Responden Berdasarkan Tingkat Pendidikan.

\begin{tabular}{cccc}
\hline No. & Tingkat pendidikan & Jumlah & Persentase (\%) \\
\hline 1. & $\begin{array}{c}\text { Rendah } \\
\text { (SD-SMP/MTs) } \\
\text { Menengah } \\
\text { (SMA/SMK) }\end{array}$ & 29 & 20 \\
3. & $\begin{array}{c}\text { Tinggi } \\
\text { (D3/S1) }\end{array}$ & 3 & 72,5 \\
\hline & Total & 40 & 7,5 \\
\hline
\end{tabular}

Sumber: Data primer penelitian 2021

7,5

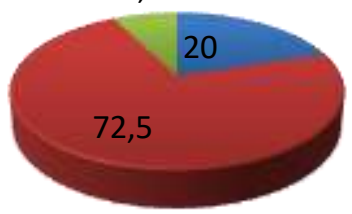

Rendah (SD-

SMP/MTs)

M Menengah

(SMA/SMK)

- Tinggi (D3/S1)

Gambar 3. Persentase jumlah responden berdasarkan tingkat pendidikan. 


\section{Volume 1, Nomor 11, November 2021 p-ISSN 2774-7018; e-ISSN 2774-700X}

Hasil tabel 3 menunjukan bahwa responden terbanyak ada pada tingkat pendidikan menengah yaitu SMA/SMK sebesar 72,5\%, sedangkan responden terkecil ada pada tingkat pendidikan tinggi yaitu D3/S1 sebesar 7,5\%.

Usia seseorang juga mempengaruhi terhadap daya tangkap dan pola pikir seseorang, Semakin bertambah usia akan semakin berkembang pula daya tangkap dan pola pikirnya, sehingga pengetahuan yang diperolehnya semakin baik, pada usia 20-35 tahun, individu akan lebih berperan aktif dalam masyarakat dan kehidupan sosial serta lebih banyak melakukan persiapan demi suksesnya upaya menyesuaikan diri menuju usia tua (Lukitasari \& Hidayati, 2013). Selain itu mereka akan lebih banyak menggunakan banyak waktu untuk membaca. Kemampuan intelektual, pemecahan masalah dan kemampuan verbal dilaporkan hampir tidak ada penurunan pada usia ini.

Tabel 4. Tingkat pengetahuan berdasarkan umur.

\begin{tabular}{ccccccccc}
\hline No. & Umur & F & \multicolumn{6}{c}{ Tingkat Pengetahuan } \\
\cline { 4 - 9 } & & & Baik & $\%$ & Cukup & $\%$ & Kurang & $\%$ \\
\hline 1 & $\begin{array}{c}\text { Dewasa } \\
\text { awal } \\
(18-40\end{array}$ & 26 & 9 & 22,5 & 11 & 27,5 & 6 & 15 \\
& & & & & & & \\
& tahun) & & & & & & & \\
\hline 2 & $\begin{array}{c}\text { Dewasa } \\
\text { akhir } \\
(41-65\end{array}$ & 14 & 3 & 7.5 & 4 & 10 & 7 & 17,5 \\
& & & & & & & \\
& tahun) & & & & & & & \\
\hline & Total & 40 & 12 & 30 & 15 & 37,5 & 13 & 32,5 \\
\hline
\end{tabular}

Sumber: Data primer penelitian 2021

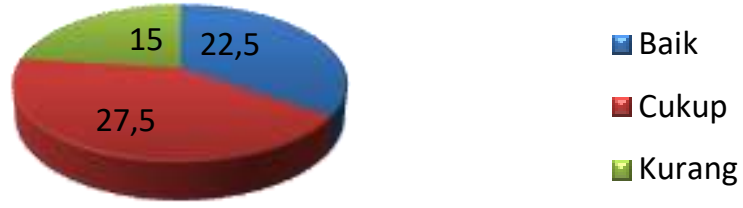

Gambar 4. Persentase tingkat pengetahuan berdasarkan umur dewasa awal (18-40 tahun)

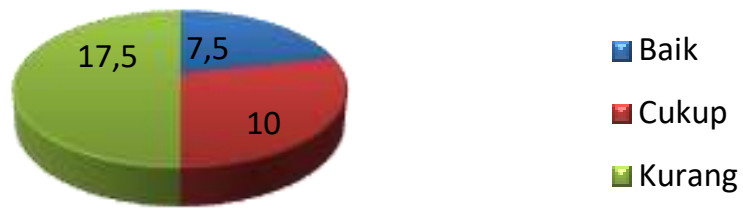

Gambar 5. Persentase tingkat pengetahuan berdasarkan umur dewasa akhir (41-65 tahun)

Tabel 4 menunjukan bahwa pada umur 18-40 tahun tingkat pengetahuan Baik sebesar 22,5\%, pada tingkat pengetahuan cukup sebesar 27,5\% dan tingkat pengetahuan kurang 15\%. Pada usia tua 41-65 tahun tingkat pengetahuan baik 7,5\%, pada tingkat pengetahuan cukup sebesar 10\%, dan pada tingkat pengetahuan kurang sebesar 17,5\%. Dari data berikut dapat disimpulkan bahwa umur tidak mempengaruhi pengetahuan tentang Dagusibu. 
Latar belakang pendidikan dan pengalaman di masa lalu dapat mempengaruhi pola pikir seseorang, kemampuan kognitif akan membentuk cara berfikir seseorang, termasuk membentuk kemampuan untuk mempelajari atau memahami factor-faktor yang berkaitan dengan penyakit yang dideritanya, dan menggunakan pengetahuan tentang kesehatan dan penyakit yang dimilikinya untuk menjaga kesehatan diri, kemampuan kognitif juga berhubungan dengan tahap perkembangan seseorang (Potter \& Perry, 2005).

Tabel 5. Tingkat pengetahuan berdasarkan pendidikan

\begin{tabular}{|c|c|c|c|c|c|c|c|c|}
\hline \multirow[t]{2}{*}{ No. } & \multirow[t]{2}{*}{ Umur } & \multirow[t]{2}{*}{$\mathrm{F}$} & \multicolumn{6}{|c|}{ Tingkat Pengetahuan } \\
\hline & & & Baik & $\%$ & Cukup & $\%$ & Kurang & $\%$ \\
\hline 1 & $\begin{array}{l}\text { Rendah } \\
\text { (SD- } \\
\text { SMP/MTs) }\end{array}$ & 8 & 2 & 5 & 3 & 7,5 & 7 & 17,5 \\
\hline 2 & $\begin{array}{l}\text { Menengah( } \\
\text { SMA/SMK } \\
\text { ) }\end{array}$ & 29 & 10 & 25 & 11 & 27,5 & 4 & 10 \\
\hline 3. & $\begin{array}{l}\text { Tinggi } \\
\text { (D3/S1) }\end{array}$ & 3 & 2 & 5 & 1 & 2,5 & 0 & 0 \\
\hline & Total & 40 & 14 & 35 & 15 & 37,5 & 11 & 27.5 \\
\hline
\end{tabular}

Sumber: Data primer penelitian 2021

Pada tabel 5 menunjukan tingkat pengetahuan masyarakat berdasarkan pendidikan yaitu berpengetahuan baik.
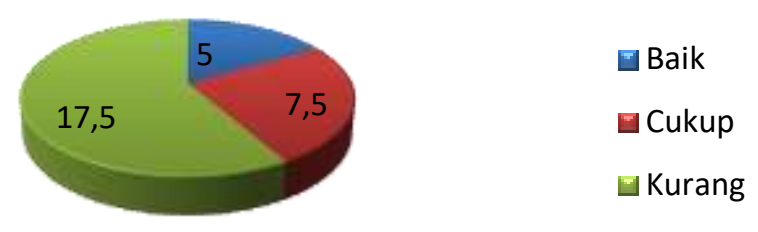

Gambar 6. Persentase tingkat pengetahuan berdasarkan tingkat pendidikan rendah (SD-SMP/MTs)
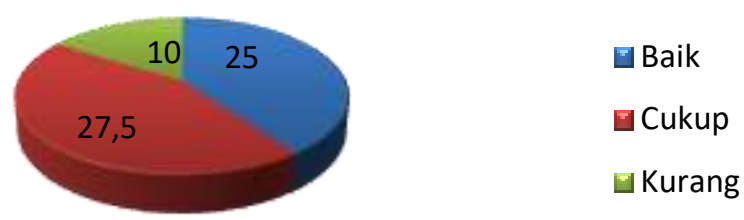

Gambar 7. Persentase tingkat pengetahuan berdasarkan tingkat pendidikan menengah (SMA/SMK) 

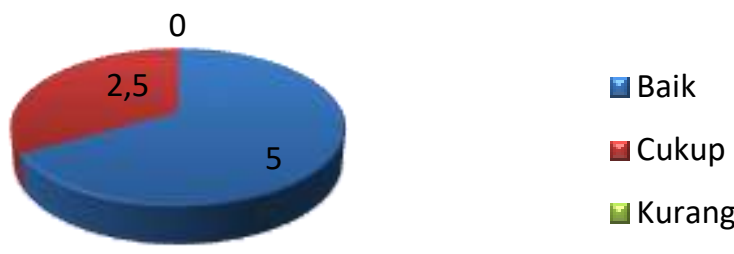

Gambar 8. Persentase tingkat pengetahuan berdasarkan tingkat pendidikan tinggi (D3/S1)

Sebesar 35\% dengan tingkat pendidikan rendah (SD-SMP/MTs) sebesar 5\%, tingkat menengah (SMA/SMK) sebesar 25\% dan tingkat tinggi sebesar 5\%. Pada tingkat pengetahuan cukup menunjukan persentase sebesar 37,5\% dengan tingkat rendah (SDSMP/MTs) sebesar 7,5\%, tingkat pengetahuan menengah (SMA/SMK) sebesar 27,5\% dan tingkat pengetahuan tinggi (D3/S1) sebesar 2,5\%. Pada tingkat pengetahuan rendah sebesar $27,5 \%$ dengan tingkat pendidikan rendah (SD-SMP/MTs) sebesar $17,5 \%$ dan pendidikan tingkat menengah sebesar (SMA/SMK) $10 \%$.

Berdasarkan hasil penelitian yang telah penulis lakukan dapat dijelaskan bahwa umur merupakan faktor yang dapat mempengaruhi tingkat pengetahuan seseorang, sebagaimana hasil penelitian diketahui umur responden berada pada kelompok dewasa akhir sebanyak (35\%), dimana hal ini dapat menjelaskan bahwa semakin berumur seseorang biasanya mempunyai pengalaman yang lebih banyak dibandingkan dengan seseorang degan umur yang masih muda, selain itu semakin tua umur seseorang pengetahuan yang diperoleh atau informasi yang didapatnya semakin banyak, terlebih didukung dengan keinginan untuk mencari informasi yang baru terkait tentang Dagusibu (Yeni, 2015).

Menurut penulis, sebagaimana hasil penelitian dapat dijelaskan pada responden rendahnya pengetahuan tentang DAGUSIBU jika ditinjau dari tingkat pendidikan sebagaimana hasil penelitian yang telah dilakukan dan diketahui berada pada jenjang menengah (27,5\%), sehingga berdampak pada infomasi yang diketahuinya tentang prinsip Dagusibu, karena keterbatasa informasi secara formal yang diperoleh. Padahal diketahui tingkat pendidikan merupakan salah satu faktor yang dapat mempengaruhi tingkat pengetahuan seseorang, dimana pendidikan pada diri individu akan berpengaruh terhadap kemampuan berfikir, semakin tinggi tingkat pendidikan akan semakin mudah berfikir rasionalisme dan menangkap informasi baru termasuk dalam menguraikan masalah yang baru. Diharapkan bagi seorang dengan tingkat pendidikan yang tinggi juga memiliki pengetahuan yang luas termasuk pengetahuan terhadap kebutuhan kesehatannya. Latar belakang pendidikan dan pengalaman di masa lalu juga dapat mempengaruhi pola pikir seseorang, kemampuan kognitif akan membentuk cara berfikir seseorang.

\section{Kesimpulan}

Hasil dari penelitian bertujuan untuk mengetahui pasien tentang Dagusibu obat berdasarkan umur dan tingkat pendidikan di Klinik Rita Medika Cisirung periode AprilMei 2021 menunjukan bahwa tingkat pengetahuan pasien berdasarkan umur, berpengetahuan kurang sebesar $27,5 \%$. Sedangkan pada tingkat pengetahuan berdasarkan pendidikan persentase berpengatahuan kurang sebesar 32,5\%. TTK yang bertugas dalam pemberian obat kepada pasien selalu memberikan edukasi kepada pasien sehingga tingkat pengetahuan pasien terhadap Dagusibu obat dan swamedikasi tidak terlalu rendah. 


\section{Bibliografi.}

Ardika, Eliza, \& Suwandewi, Alit. (2021). DAGUSIBU (Get, Use, Save, Throw) Medicine Socialization In Sungai Tabuk District, Lok Baintan Luar Village. Prosiding Pengembangan Masyarakat Mandiri Berkemajuan Muhammadiyah (Bamara-Mu), $1(1), 279-282$.

Asnasari, Linda. (2017). Hubungan Pengetahuan Tentang Swamedikasi Dengan Pola Penggunaan Obat Pada Masyarakat Dusun Kenaran, Sumberharjo, Prambanan, Sleman, Yogyakarta. Yogyakarta. Skripsi. Fakultas Frmasi Universitas Sanata Dharma.

Bachrun, Edy. (2017). Hubungan dukungan keluarga dengan kepatuhan minum obat antiretroviral pada orang dengan HIV/AIDS (ODHA). 2-Trik: Tunas-Tunas Riset Kesehatan, 7(1), 57-61.

Dewi, Ervina, Agustina, Rahmi, \& Husna, Miftahul. (2020). Studi Etnofarmakologi Tanaman Binahong (Anredera cordifolia) di Kemukiman Bambi Kabupaten Pidie Sebagai Upaya Swamedikasi. Jurnal Real Riset, 2(3).

Diantami, Aldini Yunita Mia. (2018). Pengaruh Metode Brainstorming Terhadap Tingkat Pengetahuan Dan Rasionalitas Penggunaan Obat Swamedikasi. Surabaya: Universitas Airlangga.

Khairiyati, Laily. (2015). Faktor yang berhubungan dengan penyimpanan obat keras dan obat antibiotika tanpa resep di Provinsi Gorontalo (analisis data riskesdas 2013). Jurnal Publikasi Kesehatan Masyarakat Indonesia, 2(1).

Khuluq, Husnul. (2020). Gambaran Tingkat Pengetahuan Swamedikasi Analgesik Pada Masyarakat Desa Tanjungsari, Petanahan, Kabupaten Kebumen. Jurnal Ilmiah Kesehatan Keperawatan, 15(2), 50-54.

Lukitasari, Puri, \& Hidayati, Eni. (2013). Perbedaan Pengetahuan Keluarga Tentang Cara Merawat Pasien Sebelum Dan Sesudah Kegiatan Family Gathering Pada Halusinasi Dengan Klien Skizofrenia Diruang Rawat Inap Rumah Sakit Jiwa Daerah Dr Amino Gondohutomo Semarang. Jurnal Keperawatan Jiwa (JKJ): Persatuan Perawat Nasional Indonesia, 1(1).

Majid, Abdul. (2020). Bahaya Penyalahgunaan Narkoba. Alprin.

Puspaningrum, Nabila. (2020). Faktor Ketidakpatuhan Minum Obat Pada Penderita Hiv/Aids Berdasarkan Pengetahuan Pegawai Puskesmas Poncol Semarang. Semarang: UNIMUS.

Shelawati, Shelawati. (2019). Implementasi Algoritma Skip Search Pada Sistem Pencarian Jenis Obat Berbasis Mobile. Informasi Dan Teknologi Ilmiah (INTI), 7(1), 80-83.

Soleha, Maratu, Isnawati, Ani, Fitri, Nyoman, Adelina, Rosa, Soblia, Hamim Tsalis, \& Winarsih, Winarsih. (2018). Profil penggunaan obat antiinflamasi nonstreoid di Indonesia. Jurnal Kefarmasian Indonesia, 109-117.

Tumiwa, Novita N. G. (2014). Pelayanan informasi obat terhadap kepatuhan minum obat pasien geriatri di instalasi rawat inap RSUP Prof. Dr. RD Kandou Manado. PHARMACON, 3(3).

Utami, Prapti. (2012). Antibiotik alami untuk mengatasi aneka penyakit. AgroMedia.

Yeni, Pocut Susila Indra. (2015). Faktor-faktor yang berhubungan dengan pengetahuan penggunaan obat generik pada masyarakat di wilayah kerja Puskesmas Padang Panyang Kabupaten Nagan Raya tahun 2015 [skripsi]. Kabupaten Nagan Raya: Universitas Teuku Umar. 
This work is licensed under a Creative Commons Attribution-ShareAlike 4.0 International License. 